\title{
World Bank backs Third World centres of excellence plan
}

[WASHINGTON] A global chain of so-called Millennium Institutes, acting as scientific centres of excellence in developing countries to galvanize a rapid increase in their scientific and technical strength, is being planned by the World Bank, private foundations and several governments.

The World Bank could grant the first loan, of around US $\$ 5$ million, to establish prototypes for such institutes in Chile as early as next month, according to bank officials. The initiative has the strong personal support of Eduardo Frei, the president of Chile, and James Wolfensohn, the bank's president.

The institutes will be characterized by the fact that leading scientists from outside the host country will select their directors and review their performance, that the focus of research will be of direct relevance to that country's economic and social needs, and that there will be frequent exchange of students and researchers with institutes abroad.

Frei has been discussing ideas for new scientific collaboration with other Latin American leaders for more than a year (see Nature $391,524-525 ; 1998)$. Wolfensohn, who is on the board of directors at the Institute for Advanced Study (IAS) at Princeton, New Jersey, and has been instrumental in focusing the bank on the 'knowledge gap' between industrialized and developing countries (see Nature 395, 529; 1998), badly wants to bolster science in the bank's client countries.

Wolfensohn asked IAS director Philip Griffiths to investigate the possibility of new types of institutes to do this. Earlier this year Griffiths met Claudio Teitelboim, Frei's science adviser. Their discussion led to the convergence of the two initiatives at a special meeting in June in Santiago, attended by scientific leaders from Latin America, the United States and Europe.

The meeting resulted in a concept for the Millennium Institutes which, supporters

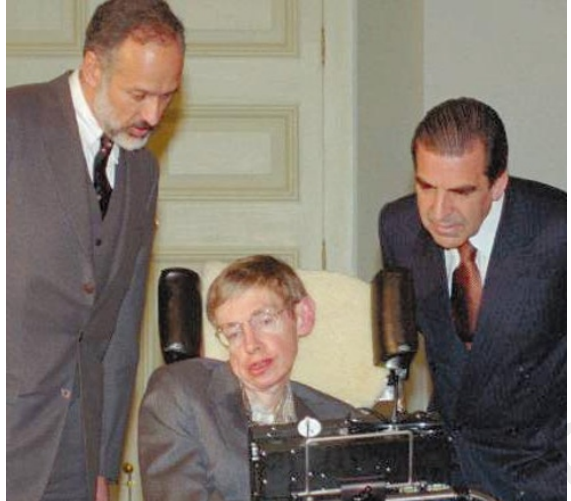

Supporting the best: Chile's president Eduardo Frei (right) and science adviser Claudio Teitelboim meet physicist Stephen Hawking.

believe, will enable a small number of excellent researchers in developing countries to break free from the constraints on first-class international research there.

They believe this can be achieved by investing a relatively small amount of money, directed at exceptional talent with guaranteed long-term support and subject to review by leading scientists from other countries.

"We want to have a research group working happily and feeling that they are not hindered by being in Chile rather than in Paris, New York or London," says Teitelboim.

Teitelboim says Chile's proposal is "a Chilean initiative that has the support of the World Bank". But bank officials and other advocates of the Millennium Institutes expect it to be rapidly followed by similar institutes elsewhere in Latin America, and that if successful, the concept will quickly spread to other regions of the world, including East Asia and Africa.

Bruce Alberts, the president of the US National Academy of Sciences, who attended the Santiago meeting, says that international peer review of the Millennium Institutes will

\section{Germany's nuclear secrets can now be told}

[MUNICH] Formerly secret documents relating to Germany's nuclear programme between 1938 and 1945 were transferred to Munich's Deutsches Museum last week. The documents include research reports and experimental protocols written by Germany's Nobel prizewinners Werner Heisenberg and Otto Hahn, as well as their correspondence with the government.

In 1938 Hahn, Lise Meitner and Fritz Strassmann discovered the first evidence of the products of uranium nuclear fission.
After the beginning of the Second World War, the Nazis increased support for the nuclear research programme. The documents show that until the early 1940s Germany and the United States were almost equally advanced in nuclear research.

Immediately after the war the Americans confiscated the documents, but they were returned to Germany in the 1970s and kept at the Karlsruhe National Research Centre. The museum will make the documents freely available to historians. Quirin Schiermeier "keep out the politics that dominates science in developing countries".

He adds that the institutes will seek to transform the public image of science in these countries, where it is sometimes viewed as isolated from and subservient to economic and societal needs. "They'll need to demonstrate value beyond just their academic value," he says. "We want them to help bring science into the public consciousness." The institutes will "be embedded in the university system" of their host countries, where their staff will be expected to teach.

Lauritz Holm-Nielsen, a senior science and technology specialist at the World Bank who runs the initiative there, says its rate of expansion will depend on the interest expressed by the bank's client countries. "We're trying at first to work with Chile, Argentina, Brazil and Colombia," he says.

Holm-Nielsen adds that the institutes will not adhere to any particular model or structure, but will instead focus on supporting the best people, using "a variety of models" applicable to individual countries. The bank will expect host governments to adopt a policy of long-term support for the institutes.

It will rapidly consider small "learning and innovation" loans, such as that requested by Chile, to start prototypes, and then larger loans for the long-term operation of the institutes. One researcher familiar with the programme expects Chile to request $\$ 40-\$ 60$ million to operate its first batch of institutes.

Griffiths says several private foundations, including the Carnegie Corporation and the Fulbright programme, are involved in the discussions on the initiative or have already pledged grants to it. He hopes that around six prototype institutes will be established within a year.

For Chile, according to Teitelboim, "the key thing is to get the prototype to fly". He envisages "no more than three" prototype institutes in Chile, together with "a larger number of nuclei”, where a single investigator will be supported, and which may later evolve into full institutes. A third element of funding will support visiting students and researchers. "There will be a very small number of permanent people, and a large flow of people visiting," says Teitelboim.

The Chilean government will not decide the disciplines in which the institutes will specialize, nor their balance between pure and applied research. "To decide whether Chile should excel in this or that would defeat the purpose" of the initiative, Teitelboim says. "We should scout for talent, and then follow that talent." Colin Macilwain 